\title{
An Overview of Nanomaterials for Water and Wastewater Treatment
}

\author{
Haijiao Lu, ${ }^{1,2}$ Jingkang Wang, ${ }^{1,2}$ Marco Stoller, ${ }^{3}$ Ting Wang, ${ }^{1,2}$ \\ Ying Bao, ${ }^{1,2}$ and Hongxun Hao ${ }^{1,2}$ \\ ${ }^{1}$ National Engineering Research Center of Industry Crystallization Technology, School of Chemical Engineering and Technology, \\ Tianjin University, Tianjin 300072, China \\ ${ }^{2}$ Co-Innovation Center of Chemical Science and Engineering, Tianjin 300072, China \\ ${ }^{3}$ Department of Chemical Materials, Sapienza University of Rome, 00185 Rome, Italy
}

Correspondence should be addressed to Hongxun Hao; hongxunhao@tju.edu.cn

Received 26 April 2016; Revised 21 June 2016; Accepted 23 June 2016

Academic Editor: Mikhael Bechelany

Copyright (C) 2016 Haijiao Lu et al. This is an open access article distributed under the Creative Commons Attribution License, which permits unrestricted use, distribution, and reproduction in any medium, provided the original work is properly cited.

Due to the exceptional characteristics which resulted from nanoscale size, such as improved catalysis and adsorption properties as well as high reactivity, nanomaterials have been the subject of active research and development worldwide in recent years. Numerous studies have shown that nanomaterials can effectively remove various pollutants in water and thus have been successfully applied in water and wastewater treatment. In this paper, the most extensively studied nanomaterials, zero-valent metal nanoparticles (Ag, $\mathrm{Fe}$, and $\mathrm{Zn}$ ), metal oxide nanoparticles ( $\mathrm{TiO}_{2}, \mathrm{ZnO}$, and iron oxides), carbon nanotubes (CNTs), and nanocomposites are discussed and highlighted in detail. Besides, future aspects of nanomaterials in water and wastewater treatment are discussed.

\section{Introduction}

Generally speaking, nanomaterials describe materials of which the structural components are sized (in at least one dimension) between 1 and $100 \mathrm{~nm}$ [1]. Due to the nanoscale size of nanomaterials, their properties, such as mechanical, electrical, optical, and magnetic properties, are significantly different from conventional materials. A wide range of nanomaterials have the characteristics of catalysis, adsorption, and high reactivity.

In the past decades, nanomaterials have been under active research and development and have been successfully applied in many fields, such as catalysis [2], medicine [3], sensing [4], and biology [5]. In particular, the application of nanomaterials in water and wastewater treatment has drawn wide attention. Due to their small sizes and thus large specific surface areas, nanomaterials have strong adsorption capacities and reactivity. What is more, the mobility of nanomaterials in solution is high [6]. Heavy metals [7], organic pollutants [8], inorganic anions [9], and bacteria [10] have been reported to be successfully removed by various kinds of nanomaterials. On the basis of numerous studies, nanomaterials show great promise for applications in water and wastewater treatment. At present, the most extensively studied nanomaterials for water and wastewater treatment mainly include zero-valent metal nanoparticles, metal oxides nanoparticles, carbon nanotubes (CNTs), and nanocomposites.

\section{Nanomaterials for Water and Wastewater Treatment}

\subsection{Zero-Valent Metal Nanoparticles}

2.1.1. Silver Nanoparticles. Silver nanoparticles (Ag NPs) are highly toxic to microorganisms and thus have strong antibacterial effects against a wide range of microorganisms, including viruses [11], bacteria [10], and fungi [12]. As a good antimicrobial agent, silver nanoparticles have been widely used for the disinfection of water.

The mechanism of the antimicrobial effects of Ag NPs is not clearly known and remains under debate. In recent 


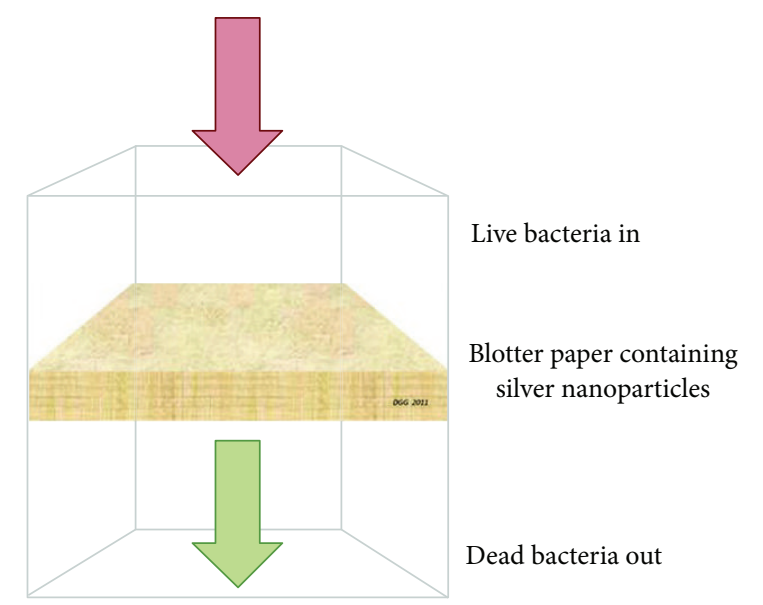

FIGURE 1: Schematic presentation of the disinfection process of blotter paper containing silver nanoparticles. Reprinted from [19] with permission. Copyright (C) 2011, American Chemical Society.

years, several theories have been put forward. Ag NPs have been reported to be able to adhere to the bacterial cell wall and subsequently penetrate it, resulting in structural changes of the cell membrane and thus increasing its permeability [13]. Besides, when Ag NPs are in contact with bacteria, free radicals can be generated. They have the ability to damage the cell membrane and are considered to cause the death of cells [14]. In addition, as DNA contains abundant sulfur and phosphorus elements, Ag NPs can act with it and thus destroy it. This is another explanation for the death of cells caused by Ag NPs [15]. What is more, the dissolution of Ag NPs will release antimicrobial $\mathrm{Ag}^{+}$ions, which can interact with the thiol groups of many vital enzymes, inactivate them, and disrupt normal functions in the cell [16].

With the development of nanotechnology, Ag NPs have been successfully applied in water and wastewater disinfection in recent years. Direct application of Ag NPs might cause some problems, such as their tendency to aggregate in aqueous media that gradually reduces their efficiency during long-term use [17]. Ag NPs attached to filter materials have been considered promising for water disinfection due to their high antibacterial activity and cost-effectiveness [18].

Via the in situ reduction of silver nitrate, Ag NPs have been deposited on the cellulose fibers of an absorbent blotting paper sheet (see Figure 1). The Ag NPs sheets showed antibacterial properties towards suspensions of Escherichia coli and Enterococcus faecalis and inactivated bacteria during filtration through the sheet. Moreover, the silver loss from the Ag NPs sheets was lower than the standards for silver in drinking water put forward by Environmental Protection Agency (EPA) and World Health Organization (WHO) [19]. Therefore, for water contaminated by bacteria, filtration through paper deposited with Ag NPs could be an effective emergency water treatment. Besides, Ag NPs synthesized by chemical reduction have been incorporated into polyethersulfone (PES) microfiltration membranes. The activity of microorganisms nearby the membranes was observed to be
TABLE 1: The standard reduction potentials of different metals ${ }^{\mathrm{a}}$.

\begin{tabular}{lc}
\hline Metal & Standard reduction potential $\left(E^{0} / \mathrm{V}\right)$ \\
\hline $\mathrm{Fe}$ & -0.440 \\
$\mathrm{Zn}$ & -0.762 \\
$\mathrm{Al}$ & -1.677 \\
$\mathrm{Ni}$ & -0.236 \\
\hline a
\end{tabular}

${ }^{\mathrm{a}}$ The data comes from [40].

remarkably suppressed. The PES-Ag NPs membranes exhibited strong antimicrobial properties and held great potential in application for water treatment [20].

In the past twenty years, Ag NPs on ceramic materials/membranes have drawn substantial attention due to their disinfection and biofouling reduction for household (pointof-use) water treatment [21]. For instance, the addition of Ag NPs to ceramic filters constructed with clay and sawdust has turned out to be able to improve the removal efficiency of Escherichia coli. It was also found that filters with higher porosity achieved higher bacteria removal than those with lower porosity [22]. Besides, colloidal Ag NPs have been combined with cylindrical ceramic filters, which were made up of clay-rich soil with water, grog, and flour, in different quantities and ways (dipping and painting). It was proved that colloidal Ag NPs improved the filter performance and the filters can remove Escherichia coli in the rate between 97.8\% and $100 \%$ [23]. Recently, the attachment of Ag NPs to ceramic membranes has been successfully predicted by DerjaguinLandau-Verwey-Overbeek (DLVO) approximation methods [24]. Further studies on Ag NPs will promote their applications in water and wastewater treatment.

2.1.2. Iron Nanoparticles. In recent years, various zero-valent metal nanoparticles, such as $\mathrm{Fe}, \mathrm{Zn}, \mathrm{Al}$, and $\mathrm{Ni}$, in water pollution treatment have drawn wide research interest. The standard reduction potentials of $\mathrm{Fe}, \mathrm{Al}, \mathrm{Ni}$, and $\mathrm{Zn}$ are listed in Table 1. Due to the extremely high reductive ability, nanozero-valent $\mathrm{Al}$ is thermodynamically unstable in the presence of water, which favors the formation of oxides/hydroxides on the surface, impeding (completely) the transfer of electrons from the metal surface to the contaminants [25]. Compared with $\mathrm{Fe}, \mathrm{Ni}$ has a less negative standard reduction potential, indicating a lower reducing ability. With a moderate standard reduction potential, nano-zero-valent $\mathrm{Fe}$ or $\mathrm{Zn}$ holds good potential to act as reducing agents relative to many redox-labile contaminants. Despite a weaker reduction ability, Fe possesses many prominent advantages over $\mathrm{Zn}$ for applications in water pollution treatment, including excellent adsorption properties, precipitation and oxidation (in the presence of dissolved oxygen), and low cost. Therefore, zerovalent iron nanoparticles have been the most extensively studied zero-valent metal nanoparticles.

As a result of the extremely small size and thus large specific surface area, nZVI possesses good adsorption properties and strong reducing ability [26]. These characteristics contribute most to its excellent performance in the removal of contaminants. Under anaerobic conditions, as shown in (1)(2), $\mathrm{Fe}^{0}$ can be oxidized by $\mathrm{H}_{2} \mathrm{O}$ or $\mathrm{H}^{+}$and generates $\mathrm{Fe}^{2+}$ 
and $\mathrm{H}_{2}$, both of which are also potential reducing agents for contaminants. In the oxidation-reduction reaction between nZVI and contaminants, $\mathrm{Fe}^{2+}$ will be oxidized to $\mathrm{Fe}^{3+}$, which can form $\mathrm{Fe}(\mathrm{OH})_{3}$ with the increase of $\mathrm{pH}$. As a common and effective flocculant, $\mathrm{Fe}(\mathrm{OH})_{3}$ facilitates the removal of contaminants, for example, $\mathrm{Cr}(\mathrm{VI})$ [27]. What is more, ZVI can degrade and oxidize a variety of organic compounds in the presence of dissolved oxygen (DO) since ZVI transfers two electrons to $\mathrm{O}_{2}$ to produce $\mathrm{H}_{2} \mathrm{O}_{2}$ (see (3)). The resultant $\mathrm{H}_{2} \mathrm{O}_{2}$ can be reduced to $\mathrm{H}_{2} \mathrm{O}$ by ZVI (see (4)). Moreover, the combination of $\mathrm{H}_{2} \mathrm{O}_{2}$ and $\mathrm{Fe}^{2+}$ (known as Fenton reaction) can generate hydroxyl radicals $\left(\mathrm{HO}^{\circ}\right)$ which have strong oxidizing ability towards a wide range of organic compounds (see (5)) [28]:

$$
\begin{aligned}
\mathrm{Fe}^{0}+2 \mathrm{H}_{2} \mathrm{O} & \longrightarrow \mathrm{Fe}^{2+}+\mathrm{H}_{2}+2 \mathrm{OH}^{-} \\
\mathrm{Fe}^{0}+2 \mathrm{H}^{+} & \longrightarrow \mathrm{Fe}^{2+}+\mathrm{H}_{2} \\
\mathrm{Fe}^{0}+\mathrm{O}_{2}+2 \mathrm{H}^{+} & \longrightarrow \mathrm{Fe}^{2+}+\mathrm{H}_{2} \mathrm{O}_{2} \\
\mathrm{Fe}^{0}+\mathrm{H}_{2} \mathrm{O}_{2}+2 \mathrm{H}^{+} & \longrightarrow \mathrm{Fe}^{2+}+2 \mathrm{H}_{2} \mathrm{O} \\
\mathrm{Fe}^{2+}+\mathrm{H}_{2} \mathrm{O}_{2} & \longrightarrow \mathrm{Fe}^{3+}+\mathrm{HO}^{-}+\mathrm{OH}^{-}
\end{aligned}
$$

With the effects of adsorption, reduction, precipitation, and oxidation (in the presence of DO), nZVI has been successfully applied in the removal of a large range of contaminants, including halogenated organic compounds [29], nitroaromatic compounds [30], organic dyes [31], phenols [32], heavy metals [33], inorganic anions such as phosphates [34] and nitrates [35], metalloids [36], and radio elements [37]. What is more, research on the application of nZVI in water and wastewater treatment is not limited to water or laboratory tests. In recent years, nZVI has also been applied in soil remediation [38] and already achieved pilot-scale and full-scale applications at real water contaminated field sites [39].

Despite many advantages, nZVI also has its own disadvantages, such as aggregation, oxidation, and separation difficulty from the degraded system. To solve these problems, various modification approaches have been put forward to enhance the performance of nZVI in water and wastewater treatment. Common modification approaches mainly include doping with other metals, surface coating, conjugation with supports, encapsulation in matrix, and emulsification [41]. Doping with other metals is supposed to enhance the reactivity of nZVI [42]. Both surface coating and conjugation with supports can prevent aggregation and enhance the dispersibility of nZVI [43, 44]. Besides, both conjugation with supports and encapsulation in matrix facilitate the separation of nZVI from the degraded system $[45,46]$. In addition, the emulsification of nZVI is aimed at solving the delivery problem of $\mathrm{nZVI}$ in dense nonaqueous phase liquid (DNAPL) [47].

2.1.3. Zinc Nanoparticles. Although most studies on contaminant degradation in water and wastewater treatment by zerovalent metal nanoparticles have been focused on iron, $\mathrm{Zn}$ has also been considered as an alternative [48]. With a more negative standard reduction potential (Table 1 ), $\mathrm{Zn}$ is a stronger reductant compared with Fe. Therefore, the contaminant degradation rate of zinc nanoparticles may be faster than that of nZVI.

For the application of nano-zero-valent zinc (nZVZ), most studies have been focused on dehalogenation reaction. Research indicated that the reduction rates of $\mathrm{CCl}_{4}$ by nZVZ were more significantly affected by solution chemistry than particle size or surface morphology. By comparing the reactivity of various types of $\mathrm{nZVI}$ and $\mathrm{nZVZ}$, it was found that $\mathrm{nZVZ}$ could degrade $\mathrm{CCl}_{4}$ more rapidly and completely than nZVI under favorable conditions [49]. Besides, a study has been carried out to examine the degradation of octachlorodibenzo-p-dioxin (OCDD) in water with four different zero-valent metal nanoparticles: zero-valent zinc (nZVZ), zero-valent iron (nZVI), zero-valent aluminum (nZVAL), and zero-valent nickel (nZVN). On the basis of experimental results, only $n Z \mathrm{VZ}$ was able to efficiently degrade OCDD into lower chlorinated congeners and thus became the first reported zero-valent metal nanoparticles suitable for OCDD dechlorination under ambient conditions [48].

However, although several studies have demonstrated that contaminant reduction by $\mathrm{nZVZ}$ could be successful, the application of $\mathrm{nZVZ}$ is mainly limited in the degradation of halogenated organic compounds, especially $\mathrm{CCl}_{4}$. The treatment of other kinds of contaminants by nZVZ has rarely been reported up to now. Therefore, pilot-scale or full-scale applications of $n Z V Z$ have not been achieved at contaminated field sites yet [49].

\subsection{Metal Oxides Nanoparticles}

2.2.1. $\mathrm{TiO}_{2}$ Nanoparticles. As an emerging and promising technology, photocatalytic degradation has attracted great attention since 1972 when Fujishima and Honda [50] observed electrochemical photolysis of water on $\mathrm{TiO}_{2}$ semiconductor electrode. In recent years, photocatalytic degradation technology has been successfully applied in the contaminant degradation in water and wastewater. At the presence of light and catalyst, contaminants can be gradually oxidized into low molecular weight intermediate products and eventually transformed into $\mathrm{CO}_{2}, \mathrm{H}_{2} \mathrm{O}$, and anions such as $\mathrm{NO}_{3}{ }^{-}, \mathrm{PO}_{4}{ }^{3-}$, and $\mathrm{Cl}^{-}$.

The majority of common photocatalysts are metal oxide or sulfide semiconductors, among which $\mathrm{TiO}_{2}$ has been most extensively investigated in the past decades. Owing to its high photocatalytic activity, reasonable price, photostability, and chemical and biological stability [51-53], $\mathrm{TiO}_{2}$ is the most exceptional photocatalyst to date. The large band gap energy $(3.2 \mathrm{eV})$ of $\mathrm{TiO}_{2}$ requires ultraviolet (UV) excitation to induce charge separation within the particles. As shown in Figure 2, upon UV irradiation, $\mathrm{TiO}_{2}$ will generate reactive oxygen species (ROS) which can completely degrade contaminants in very short reaction time. Besides, $\mathrm{TiO}_{2}$ NPs show little selectivity and thus are suitable for the degradation of all kinds of contaminants, such as chlorinated organic compounds [54], polycyclic aromatic hydrocarbons [55], dyes [56], phenols [57], pesticides [58], arsenic [59], cyanide [60], 


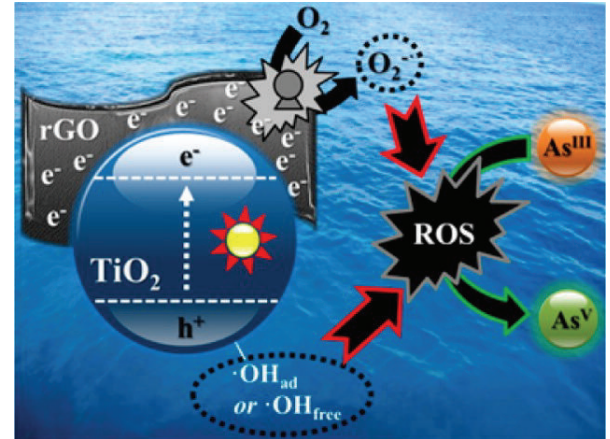

FIGURE 2: Schematic presentation of the mechanism of $\mathrm{TiO}_{2}$ photocatalytic process. Reprinted from [59] with permission. Copyright (c) 2014, American Chemical Society.

and heavy metals [61]. What is more, hydroxyl radicals generated under UV irradiation $(\lambda<400 \mathrm{~nm})$ enable $\mathrm{TiO}_{2}$ NPs to damage the function and structure of various cells [62]. The photocatalytic properties of $\mathrm{TiO}_{2} \mathrm{NPs}$ are able to kill a wide array of microorganisms, such as Gram-negative and Gram-positive bacteria, as well as fungi, algae, protozoa, and viruses [63].

However, $\mathrm{TiO}_{2} \mathrm{NPs}$ also have some disadvantages. As mentioned above, their large band gap energy makes them need the excitation of UV and the photocatalytic properties of $\mathrm{TiO}_{2}$ NPs under visible light are relatively inconspicuous. Hence, studies have been conducted to improve the photocatalytic properties of $\mathrm{TiO}_{2}$ NPs under visible light and UV. For example, metal doping has been demonstrated to be able to improve the visible light absorbance of $\mathrm{TiO}_{2}$ NPs [64] and increase their photocatalytic activity under UV irradiation [65]. Among various metals, Ag has received much attention for metal doping of $\mathrm{TiO}_{2} \mathrm{NPs}_{\text {because it could }}$ enable the visible light excitation of $\mathrm{TiO}_{2} \mathrm{NPs}$ [66] and greatly improve the photocatalytic inactivation of bacteria [67] and viruses [68]. Besides, modifications of $\mathrm{TiO}_{2} \mathrm{NPs}$ by nonmetal elements, such as N, F, S, and C, have also been found to be able to narrow the band gap significantly, enhance adsorption in the visible region, and improve the degradation of dyes under visible light irradiation, especially under natural solar light irradiation [69].

Besides, the production process of $\mathrm{TiO}_{2} \mathrm{NPs}$ is rather complicated. What is more, it is difficult to recover $\mathrm{TiO}_{2} \mathrm{NPs}$ from the treated wastewater, especially when they are used in suspension. In recent years, more and more efforts have been devoted to surmounting this problem. Among them, the coupling of the photocatalysis of $\mathrm{TiO}_{2} \mathrm{NPs}$ with membrane technology has attracted much attention and shown promise for overcoming the recovery problem of $\mathrm{TiO}_{2} \mathrm{NPs}$. A wide range of membranes have been incorporated with $\mathrm{TiO}_{2} \mathrm{NPs}$, such as poly(vinylidene fluoride) [70, 71], polyethersulfone [72, 73], polymethyl methacrylate [74], and poly(amide-imide) [75]. For instance, using $\mathrm{N} \mathrm{N}^{\prime}$-methylenebisacrylamide as the cross-linker and ammonium persulphate as the initiator pair, the polymerization of acrylamide in an aqueous solution was carried out to synthesize $\mathrm{TiO}_{2}$ /poly[acrylamide-co-(acrylic acid)] composite hydrogel. Methylene blue was successfully removed by the photocatalysis of $\mathrm{TiO}_{2} \mathrm{NPs}$. Moreover, due to the coupling with polymeric membranes, $\mathrm{TiO}_{2} \mathrm{NPs}$ could be easily separated from the treated system through a simple filtration [76]. A detailed review on $\mathrm{TiO}_{2}$ nanocomposite based polymeric membranes has been presented [77]. More recently, doped $\mathrm{TiO}_{2}$ magnetic nanoparticles have been synthesized in a spinning disk reactor to achieve a feasible recovery of the nanoparticles by a magnetic trap [78, 79]. The production process is continuous and thus suitable for industrial applications [79].

2.2.2. $\mathrm{ZnO}$ Nanoparticles. In the field of photocatalysis, apart from $\mathrm{TiO}_{2} \mathrm{NPs}, \mathrm{ZnO}$ NPs have emerged as another efficient candidate in water and wastewater treatment because of their unique characteristics, such as direct and wide band gap in the near-UV spectral region, strong oxidation ability, and good photocatalytic property [80-82].

$\mathrm{ZnO}$ NPs are environment-friendly as they are compatible with organisms [83], which makes them suitable for the treatment of water and wastewater. Besides, the photocatalytic capability of $\mathrm{ZnO}$ NPs is similar to that of $\mathrm{TiO}_{2}$ NPs because their band gap energies are almost the same [84]. However, $\mathrm{ZnO}$ NPs have the advantage of low cost over $\mathrm{TiO}_{2}$ NPs [84]. Moreover, $\mathrm{ZnO}$ NPs can adsorb a wider range of solar spectra and more light quanta than several semiconducting metal oxides [85].

Nevertheless, similar to that of $\mathrm{TiO}_{2}$ NPs, the light absorption of $\mathrm{ZnO}$ NPs is also limited in the ultraviolet light region due to their big band gap energies. Besides, the application of $\mathrm{ZnO}$ NPs is impeded by photocorrosion, which will result in fast recombination of photogenerated charges and thus cause low photocatalytic efficiency [86].

To improve the photodegradation efficiency of $\mathrm{ZnO}$ NPs, metal doping is a common strategy. Various types of metal dopants have been tested, including anionic dopants, cationic dopants, rare-earth dopants, and codopants [87]. Besides, many studies have shown that coupling with other semiconductors, such as $\mathrm{CdO}$ [88], $\mathrm{CeO}_{2}$ [89], $\mathrm{SnO}_{2}$ [90], $\mathrm{TiO}_{2}$ [91], graphene oxide (GO) [92], and reduced graphene oxide (RGO) [93], is a feasible approach to enhance the photodegradation efficiency of $\mathrm{ZnO}$ NPs.

2.2.3. Iron Oxides Nanoparticles. In recent years, there is a growing interest in the use of iron oxides nanoparticles for the removal of heavy metal due to their simplicity and availability. Magnetic magnetite $\left(\mathrm{Fe}_{3} \mathrm{O}_{4}\right)$ and magnetic maghemite $(\gamma$ $\left.\mathrm{Fe}_{2} \mathrm{O}_{4}\right)$ and nonmagnetic hematite $\left(\alpha-\mathrm{Fe}_{2} \mathrm{O}_{3}\right)$ are often used as nanoadsorbents.

Generally, due to the small size of nanosorbent materials, their separation and recovery from contaminated water are great challenges for water treatment. However, magnetic magnetite $\left(\mathrm{Fe}_{3} \mathrm{O}_{4}\right)$ and magnetic maghemite $\left(\gamma-\mathrm{Fe}_{2} \mathrm{O}_{4}\right)$ can be easily separated and recovered from the system with the assistance of an external magnetic field. Therefore, they have been successfully used as sorbent materials in the removal of various heavy metals from water systems [94-96]. In order to increase adsorption efficiency and to avoid interference from other metals ions, iron oxides nanoparticles have 
been functionalized to tune their adsorption properties by adding various ligands (e.g., ethylenediamine tetraacetic acid (EDTA), L-glutathione (GSH), mercaptobutyric acid (MBA), $\alpha$-thio- $\omega$-(propionic acid) hepta(ethylene glycol) (PEG-SH), and meso-2,3-dimercaptosuccinic acid (DMSA)) [97] or polymers (e.g., copolymers of acrylic acid and crotonic acid) [98]. A flexible ligand shell has been reported to facilitate the incorporation of a wide array of functional groups into the shell and ensured the properties of $\mathrm{Fe}_{3} \mathrm{O}_{4}$ nanoparticles are intact [99]. Besides, a polymer shell has been found to be able to prevent aggregation of particles and improve the dispersion stability of the nanostructures [98]. Polymer molecules could act as binders for metal ions and thus became a "carrier" of metal ions from treated water [99].

Hematite $\left(\alpha-\mathrm{Fe}_{2} \mathrm{O}_{3}\right)$ has been considered as a stable and cheap material in sensors, catalysis, and environmental applications [100]. Moreover, nanohematite has also been demonstrated to be an effective adsorbent for the removal of heavy metal ions from spiked tap water [101]. 3D flower-like $\alpha-\mathrm{Fe}_{2} \mathrm{O}_{3}$ microstructures assembled from nanopetal subunits have been synthesized for water treatment use. The flowerlike $\alpha-\mathrm{Fe}_{2} \mathrm{O}_{3}$ could effectively prevent further aggregation, and the enhanced surface area with multiple spaces and pores provided many active sites to interact with contaminants. The maximum adsorption capacities of the as-prepared $\alpha-\mathrm{Fe}_{2} \mathrm{O}_{3}$ for $\mathrm{As}(\mathrm{V})$ and $\mathrm{Cr}(\mathrm{VI})$ were much higher than those of many previously reported nanomaterials [100].

2.3. Carbon Nanotubes. Carbon nanomaterials (CNMs) are a class of fascinating materials due to their unique structures and electronic properties which make them attractive for fundamental studies as well as diverse applications, especially in sorption processes. Their advantages for water and wastewater treatment are due to (1) great capacity to adsorb a wide range of contaminants, (2) fast kinetics, (3) large specific surface area, and (4) selectivity towards aromatics [6]. There are several forms of CNMs, such as carbon nanotubes (CNTs), carbon beads, carbon fibers, and nanoporous carbon [6]. Among them, CNTs have attracted the most attentions and progressed rapidly in recent years.

Carbon nanotubes are graphene sheets rolled up in cylinders with diameter as small as $1 \mathrm{~nm}$ [102]. CNTs have attracted great interest as an emerging adsorbent due to their unique properties. With an extremely large specific surface area and abundant porous structures, CNTs possess exceptional adsorption capabilities and high adsorption efficiencies for numerous kinds of contaminants, such as dichlorobenzene [103], ethyl benzene [104], $\mathrm{Zn}^{2+}$ [105], $\mathrm{Pb}^{2+}, \mathrm{Cu}^{2+}$, and $\mathrm{Cd}^{2+}$ [106], and dyes [107]. According to their (super)structures, CNTs can be classified into two types (Figure 3): (1) multiwalled carbon nanotubes (MWCNTs), which comprised multiple layers of concentric cylinders with a spacing of about $0.34 \mathrm{~nm}$ between the adjacent layers, and (2) single-walled carbon nanotubes (SWCNTs), which consist of single layers of graphene sheets seamlessly rolled into cylindrical tubes [108]. In recent years, both MWCNTs [105-107] and SWCNTs [109] have been applied for the removal of contaminants in water.
To improve the adsorption, mechanical, optical, and electrical properties, carbon nanotubes are often combined with other metals or types of support [110]. The functionalization increases the number of oxygen, nitrogen, or other groups on the surface of CNTs, enhances their dispersibility, and thus improves specific surface area [111-113]. For example, a study using CNTs as a support for magnetic iron oxide has been reported by Gupta et al. [114]. Combining the adsorption properties of CNTs with the magnetic properties of iron oxide, a "composite" adsorbent was prepared to remove chromium from water. Apart from owning excellent adsorption properties, the "composite" adsorbent can be easily separated from water via an external magnetic field.

In spite of the exceptional properties of CNTs, the development and applications of CNTs are mainly limited by their low volume of production and high cost. Besides, CNTs cannot be used alone without any supporting medium or matrix to form structural components [102].

2.4. Nanocomposites. As mentioned above, every nanomaterial has its own drawbacks. For example, nZVI has the disadvantages of aggregation, oxidation, and separation difficulty from the degraded systems. The light adsorption of $\mathrm{TiO}_{2} \mathrm{NPs}$ and $\mathrm{ZnO}$ NPs is limited in the ultraviolet light region due to their big band gap energies. Nanofiltration membranes are troubled by the problem of membrane fouling. Carbon nanotubes are mainly limited by their low volume of production and high cost as well as the need for supporting medium or matrix. In order to overcome these problems and achieve better removal efficiency, it is a common and effective strategy to fabricate nanocomposites for water and wastewater treatment.

In recent years, the synthesis of various nanocomposites has become the most active subject in the field of nanomaterials. On the basis of numerous studies, much progress has been made throughout the world. For example, via chemical deposition of nZVI on CNTs, a novel nanoscale adsorbent was prepared. According to the results, the adsorbent has good potential for quick and effective removal of nitrate in water. Besides, due to its unique magnetic property, the adsorbent can be easily separated from the solution by the magnet [115]. Besides, thin film nanocomposite (TFN) nanofiltration membranes have been prepared via in situ interfacial incorporation of $\mathrm{TiO}_{2}$ NPs along with fabrication of copolyamide network on a polyimide support. To improve the compatibility of $\mathrm{TiO}_{2}$ NPs inside the polymer matrix, both amine and chloride compounds were utilized to functionalize $\mathrm{TiO}_{2}$ NPs. TFN membranes exhibited higher methanol flux and dye rejection in spite of lower swelling degree. The loading of $\mathrm{TiO}_{2}$ NPs turned out to be a crucial factor on the NF membrane performance [116].

In theory, ideal composites for real applications should be continuous, bulk immobile materials of which the nanoreactivity is obtained by anchoring or impregnating a parent material structure with nanomaterials [117]. What is more, it is widely acknowledged that the treatment of water and wastewater calls for nontoxic, long-term stable and lowcost materials. To obtain desirable nanocomposites, further research is still under way. 


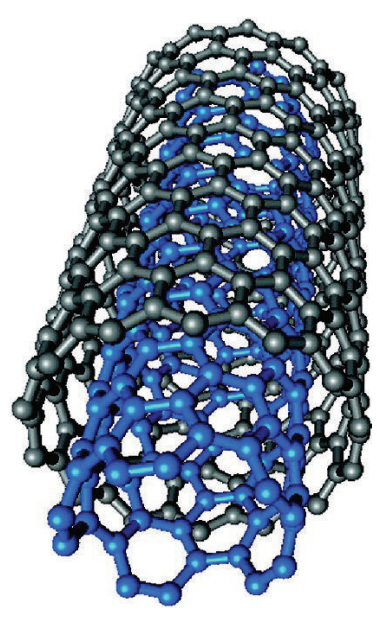

(a)

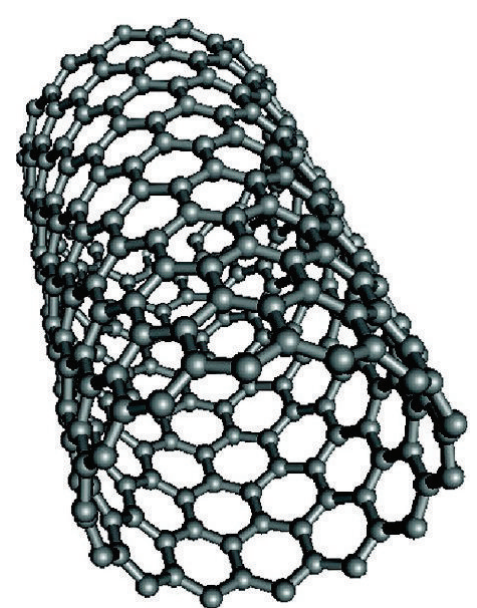

(b)

Figure 3: (Super)structure representations of (a) MWCNTs and (b) SWCNTs. Reprinted from [108] with permission. Copyright (c) 2009, American Chemical Society.

\section{Conclusions and Perspectives}

In this paper, the most extensively studied nanomaterials, zero-valent metal nanoparticles (Ag, Fe, and $\mathrm{Zn}$ ), metal oxide nanoparticles ( $\mathrm{TiO}_{2}, \mathrm{ZnO}$, and iron oxides), carbon nanotubes (CNTs), and nanocomposites were highlighted. Moreover, their applications in water and wastewater treatment were discussed in detail. Considering the current speed of development and application, nanomaterials look extremely promising for water and wastewater treatment.

However, further studies are still needed to address the challenges of nanomaterials. Up to now, only a few kinds of nanomaterials have emerged commercially. Since low production cost is crucial to ensure their wide spread applications in water and wastewater treatment, future research should be devoted to improving the economical efficiency of nanomaterials. Besides, with increasingly extensive applications of nanomaterials in water and wastewater treatment, there are growing concerns on their potential toxicity to the environment and human health. Available information in the literature has revealed that several nanomaterials may have adverse effects on the environment and human health [118-120]. Nevertheless, standards for assessing the toxicity of nanomaterials are relatively insufficient at present. Hence, comprehensive evaluation of the toxicity of nanomaterials is in urgent need to ensure their real applications. What is more, the evaluation and comparison of the performance of various nanomaterials in water and wastewater treatment are still short of uniform or recognized standards. It is difficult to compare the performances of different nanomaterials and figure out promising nanomaterials that deserve further development. Therefore, the performance evaluation mechanism of nanomaterials in water and wastewater treatment should be perfected in the future.

\section{Competing Interests}

The authors declare that there are no competing interests regarding the publication of this paper.

\section{Acknowledgments}

This research is financially supported by National Natural Science Foundation of China (no. 21376165 and no. 51478308).

\section{References}

[1] C. Buzea, I. I. Pacheco, and K. Robbie, "Nanomaterials and nanoparticles: sources and toxicity," Biointerphases, vol. 2, no. 4, pp. MR17-MR71, 2007.

[2] V. Parmon, "Nanomaterials in catalysis," Materials Research Innovations, vol. 12, no. 2, pp. 60-61, 2008.

[3] X.-J. Liang, A. Kumar, D. Shi, and D. Cui, "Nanostructures for medicine and pharmaceuticals," Journal of Nanomaterials, vol. 2012, Article ID 921897, 2 pages, 2012.

[4] A. Kusior, J. Klich-Kafel, A. Trenczek-Zajac, K. Swierczek, M. Radecka, and $\mathrm{K}$. Zakrzewska, " $\mathrm{TiO}_{2}-\mathrm{SnO}_{2}$ nanomaterials for gas sensing and photocatalysis," Journal of the European Ceramic Society, vol. 33, no. 12, pp. 2285-2290, 2013.

[5] B. Bujoli, H. Roussière, G. Montavon et al., "Novel phosphatephosphonate hybrid nanomaterials applied to biology," Progress in Solid State Chemistry, vol. 34, no. 2-4, pp. 257-266, 2006.

[6] M. M. Khin, A. S. Nair, V. J. Babu, R. Murugan, and S. Ramakrishna, "A review on nanomaterials for environmental remediation," Energy \& Environmental Science, vol. 5, no. 8, pp. 8075-8109, 2012.

[7] W.-W. Tang, G.-M. Zeng, J.-L. Gong et al., "Impact of humic/fulvic acid on the removal of heavy metals from aqueous solutions using nanomaterials: a review," Science of the Total Environment, vol. 468-469, pp. 1014-1027, 2014.

[8] J. Yan, L. Han, W. Gao, S. Xue, and M. Chen, "Biochar supported nanoscale zerovalent iron composite used as persulfate activator for removing trichloroethylene," Bioresource Technology, vol. 175, pp. 269-274, 2015.

[9] F. Liu, J. H. Yang, J. Zuo et al., “Graphene-supported nanoscale zero-valent iron: removal of phosphorus from aqueous solution and mechanistic study," Journal of Environmental Sciences, vol. 26, no. 8, pp. 1751-1762, 2014.

[10] R. S. Kalhapure, S. J. Sonawane, D. R. Sikwal et al., "Solid lipid nanoparticles of clotrimazole silver complex: an efficient 
nano antibacterial against Staphylococcus aureus and MRSA," Colloids and Surfaces B: Biointerfaces, vol. 136, pp. 651-658, 2015.

[11] B. Borrego, G. Lorenzo, J. D. Mota-Morales et al., "Potential application of silver nanoparticles to control the infectivity of Rift Valley fever virus in vitro and in vivo," Nanomedicine: Nanotechnology, Biology and Medicine, vol. 12, no. 5, pp. 11851192, 2016.

[12] C. Krishnaraj, R. Ramachandran, K. Mohan, and P. T. Kalaichelvan, "Optimization for rapid synthesis of silver nanoparticles and its effect on phytopathogenic fungi," Spectrochimica ActaPart A: Molecular and Biomolecular Spectroscopy, vol. 93, pp. 95-99, 2012.

[13] I. Sondi and B. Salopek-Sondi, "Silver nanoparticles as antimicrobial agent: a case study on E. coli as a model for Gramnegative bacteria," Journal of Colloid and Interface Science, vol. 275, no. 1, pp. 177-182, 2004.

[14] M. Danilczuk, A. Lund, J. Sadlo, H. Yamada, and J. Michalik, "Conduction electron spin resonance of small silver particles," Spectrochimica Acta-Part A: Molecular and Biomolecular Spectroscopy, vol. 63, no. 1, pp. 189-191, 2006.

[15] K. I. Dhanalekshmi and K. S. Meena, "DNA intercalation studies and antimicrobial activity of $\mathrm{Ag@OrO} \mathrm{Zr}_{2}$ core-shell nanoparticles in vitro," Materials Science and Engineering: $C$, vol. 59, pp. 1063-1068, 2016.

[16] S. Prabhu and E. K. Poulose, "Silver nanoparticles: mechanism of antimicrobial action, synthesis, medical applications, and toxicity effects," International Nano Letters, vol. 2, no. 1, p. 32, 2012.

[17] X. Li, J. J. Lenhart, and H. W. Walker, "Aggregation kinetics and dissolution of coated silver nanoparticles," Langmuir, vol. 28, no. 2, pp. 1095-1104, 2012.

[18] D. V. Quang, P. B. Sarawade, S. J. Jeon et al., "Effective water disinfection using silver nanoparticle containing silica beads," Applied Surface Science, vol. 266, pp. 280-287, 2013.

[19] T. A. Dankovich and D. G. Gray, "Bactericidal paper impregnated with silver nanoparticles for point-of-use water treatment," Environmental Science and Technology, vol. 45, no. 5, pp. 1992-1998, 2011.

[20] A. M. Ferreira, É. B. Roque, F. V. D. Fonseca, and C. P. Borges, "High flux microfiltration membranes with silver nanoparticles for water disinfection," Desalination \& Water Treatment, vol. 56, no. 13, pp. 3590-3598, 2015.

[21] D. Ren and J. A. Smith, "Retention and transport of silver nanoparticles in a ceramic porous medium used for point-ofuse water treatment," Environmental Science and Technology, vol. 47, no. 8, pp. 3825-3832, 2013.

[22] E. N. Kallman, V. A. Oyanedel-Craver, and J. A. Smith, "Ceramic filters impregnated with silver nanoparticles for point-of-use water treatment in rural guatemala," Journal of Environmental Engineering, vol. 137, no. 6, pp. 407-415, 2011.

[23] V. A. Oyanedel-Craver and J. A. Smith, "Sustainable colloidalsilver-impregnated ceramic filter for point-of-use water treatment," Environmental Science and Technology, vol. 42, no. 3, pp. 927-933, 2008.

[24] A. M. Mikelonis, S. Youn, and D. F. Lawler, "DLVO approximation methods for predicting the attachment of silver nanoparticles to ceramic membranes," Langmuir, vol. 32, no. 7, pp. 17231731, 2016.

[25] M. Rivero-Huguet and W. D. Marshall, "Reduction of hexavalent chromium mediated by micron- and nano-scale zerovalent metallic particles," Journal of Environmental Monitoring, vol. 11, no. 5, pp. 1072-1079, 2009.
[26] L. J. Matheson and P. G. Tratnyek, "Reductive dehalogenation of chlorinated methanes by iron metal," Environmental Science and Technology, vol. 28, no. 12, pp. 2045-2053, 1994.

[27] Y. Wang, Z. Fang, Y. Kang, and E. P. Tsang, "Immobilization and phytotoxicity of chromium in contaminated soil remediated by CMC-stabilized nZVI," Journal of Hazardous Materials, vol. 275, pp. 230-237, 2014.

[28] F. Fu, D. D. Dionysiou, and H. Liu, "The use of zero-valent iron for groundwater remediation and wastewater treatment: a review," Journal of Hazardous Materials, vol. 267, pp. 194-205, 2014.

[29] D.-W. Liang, Y.-H. Yang, W.-W. Xu, S.-K. Peng, S.-F. Lu, and Y. Xiang, "Nonionic surfactant greatly enhances the reductive debromination of polybrominated diphenyl ethers by nanoscale zero-valent iron: mechanism and kinetics," Journal of Hazardous Materials, vol. 278, pp. 592-596, 2014.

[30] Z. Xiong, B. Lai, P. Yang, Y. Zhou, J. Wang, and S. Fang, “Comparative study on the reactivity of $\mathrm{Fe} / \mathrm{Cu}$ bimetallic particles and zero valent iron (ZVI) under different conditions of $\mathrm{N}_{2}$, air or without aeration," Journal of Hazardous Materials, vol. 297, pp. 261-268, 2015.

[31] G. E. Hoag, J. B. Collins, J. L. Holcomb, J. R. Hoag, M. N. Nadagouda, and R. S. Varma, "Degradation of bromothymol blue by 'greener' nano-scale zero-valent iron synthesized using tea polyphenols," Journal of Materials Chemistry, vol. 19, no. 45, pp. 8671-8677, 2009.

[32] X. Y. Wang, M. P. Zhu, H. L. Liu, J. Ma, and F. Li, "Modification of Pd-Fe nanoparticles for catalytic dechlorination of 2,4dichlorophenol," Science of the Total Environment, vol. 449, pp. 157-167, 2013.

[33] M. N. Arancibia, S. E. Baltazar, A. García et al., "Nanoscale zero valent supported by Zeolite and Montmorillonite: template effect of the removal of lead ion from an aqueous solution," Journal of Hazardous Materials, vol. 301, pp. 371-380, 2016.

[34] Z. Marková, K. M. Šišková, J. Filip et al., "Air stable magnetic bimetallic Fe-Ag nanoparticles for advanced antimicrobial treatment and phosphorus removal," Environmental Science and Technology, vol. 47, no. 10, pp. 5285-5293, 2013.

[35] G. G. Muradova, S. R. Gadjieva, L. Di Palma, and G. Vilardi, "Nitrates removal by bimetallic nanoparticles in water," Chemical Engineering Transactions, vol. 47, pp. 205-210, 2016.

[36] L. Ling, B. Pan, and W.-X. Zhang, "Removal of selenium from water with nanoscale zero-valent iron: mechanisms of intraparticle reduction of Se(IV)," Water Research, vol. 71, pp. 274-281, 2015.

[37] L. Ling and W.-X. Zhang, "Enrichment and encapsulation of uranium with iron nanoparticle," Journal of the American Chemical Society, vol. 137, no. 8, pp. 2788-2791, 2015.

[38] M. T. Gueye, L. D. Palma, G. Allahverdeyeva et al., "Hexavalent chromium reduction by nano zero valent iron in soil," Chemical Engineering Transactions, vol. 47, pp. 289-294, 2016.

[39] W.-X. Zhang, "Nanoscale iron particles for environmental remediation: an overview," Journal of Nanoparticle Research, vol. 5, no. 3-4, pp. 323-332, 2003.

[40] S. G. Bratsch, "Standard electrode potentials and temperature coefficients in water at 298.15 K," Journal of Physical and Chemical Reference Data, vol. 18, no. 1, pp. 1-21, 1989.

[41] M. Stefaniuk, P. Oleszczuk, and Y. S. Ok, "Review on nano zerovalent iron (nZVI): From synthesis to environmental applications," Chemical Engineering Journal, vol. 287, pp. 618-632, 2016. 
[42] Y. H. Liou, S.-L. Lo, C.-J. Lin, W. H. Kuan, and S. C. Weng, "Chemical reduction of an unbuffered nitrate solution using catalyzed and uncatalyzed nanoscale iron particles," Journal of Hazardous Materials, vol. 127, no. 1-3, pp. 102-110, 2005.

[43] R. Singh and V. Misra, "Stabilization of zero-valent iron nanoparticles: role of polymers and surfactants," in Handbook of Nanoparticles, pp. 1-19, Springer, New York, NY, USA, 2015.

[44] Z.-X. Chen, X.-Y. Jin, Z. Chen, M. Megharaj, and R. Naidu, "Removal of methyl orange from aqueous solution using bentonite-supported nanoscale zero-valent iron," Journal of Colloid and Interface Science, vol. 363, no. 2, pp. 601-607, 2011.

[45] X. Y. Li, L. H. Ai, and J. Jiang, "Nanoscale zerovalent iron decorated on graphene nanosheets for $\mathrm{Cr}(\mathrm{VI})$ removal from aqueous solution: surface corrosion retard induced the enhanced performance," Chemical Engineering Journal, vol. 288, pp. 789-797, 2016.

[46] X. S. Lv, X. Q. Xue, G. M. Jiang et al., "Nanoscale zero-valent iron (nZVI) assembled on magnetic $\mathrm{Fe}_{3} \mathrm{O}_{4}$ /graphene for chromium (VI) removal from aqueous solution," Journal of Colloid \& Interface Science, vol. 417, pp. 51-59, 2014.

[47] N. D. Berge and C. A. Ramsburg, "Oil-in-water emulsions for encapsulated delivery of reactive iron particles," Environmental Science \& Technology, vol. 43, no. 13, pp. 5060-5066, 2009.

[48] V. Bokare, J.-L. Jung, Y.-Y. Chang, and Y.-S. Chang, "Reductive dechlorination of octachlorodibenzo-p-dioxin by nanosized zero-valent zinc: Modeling of rate kinetics and congener profile," Journal of Hazardous Materials, vol. 250-251, pp. 397-402, 2013.

[49] P. G. Tratnyek, A. J. Salter, J. T. Nurmi, and V. Sarathy, "Environmental applications of zerovalent metals: iron vs. zinc," in Nanoscale Materials in Chemistry: Environmental Applications, vol. 1045 of ACS Symposium Series, chapter 9, pp. 165-178, 2010.

[50] A. Fujishima and K. Honda, "Electrochemical photolysis of water at a semiconductor electrode," Nature, vol. 238, no. 5358, pp. 37-38, 1972.

[51] K. Guesh, Á. Mayoral, C. M. Álvarez, Y. Chebude, and I. Díaz, "Enhanced photocatalytic activity of $\mathrm{TiO}_{2}$ supported on zeolites tested in real wastewaters from the textile industry of Ethiopia," Microporous and Mesoporous Materials, vol. 225, pp. 88-97, 2016.

[52] K. Imamura, T. Yoshikawa, K. Hashimoto, and H. Kominami, "Stoichiometric production of aminobenzenes and ketones by photocatalytic reduction of nitrobenzenes in secondary alcoholic suspension of titanium(IV) oxide under metal-free conditions," Applied Catalysis B: Environmental, vol. 134-135, pp. 193-197, 2013.

[53] S. B. Rawal, S. Bera, D. Lee, D.-J. Jang, and W. I. Lee, "Design of visible-light photocatalysts by coupling of narrow bandgap semiconductors and $\mathrm{TiO}_{2}$ : effect of their relative energy band positions on the photocatalytic efficiency," Catalysis Science and Technology, vol. 3, no. 7, pp. 1822-1830, 2013.

[54] T. Ohsaka, K. Shinozaki, K. Tsuruta, and K. Hirano, "Photoelectrochemical degradation of some chlorinated organic compounds on $\mathrm{n}-\mathrm{TiO}_{2}$ electrode," Chemosphere, vol. 73, no. 8, pp. 1279-1283, 2008.

[55] M. Guo, W. Song, T. Wang, Y. Li, X. Wang, and X. Du, "Phenylfunctionalization of titanium dioxide-nanosheets coating fabricated on a titanium wire for selective solid-phase microextraction of polycyclic aromatic hydrocarbons from environment water samples," Talanta, vol. 144, pp. 998-1006, 2015.
[56] Y. Lee, S. Kim, P. Venkateswaran, J. Jang, H. Kim, and J. Kim, "Anion co-doped Titania for solar photocatalytic degradation of dyes," Carbon letters, vol. 9, no. 2, pp. 131-136, 2008.

[57] A. T. Nguyen, C.-T. Hsieh, and R.-S. Juang, "Substituent effects on photodegradation of phenols in binary mixtures by hybrid $\mathrm{H}_{2} \mathrm{O}_{2}$ and $\mathrm{TiO}_{2}$ suspensions under UV irradiation," Journal of the Taiwan Institute of Chemical Engineers, vol. 62, pp. 68-75, 2016.

[58] M. G. Alalm, A. Tawfik, and S. Ookawara, "Comparison of solar $\mathrm{TiO}_{2}$ photocatalysis and solar photo-Fenton for treatment of pesticides industry wastewater: operational conditions, kinetics, and costs," Journal of Water Process Engineering, vol. 8, pp. 55-63, 2015.

[59] G. Moon, D. Kim, H. Kim, A. D. Bokare, and W. Choi, "Platinum-like behavior of reduced graphene oxide as a cocatalyst on $\mathrm{TiO}_{2}$ for the efficient photocatalytic oxidation of arsenite," Environmental Science \& Technology Letters, vol. 1, no. 2, pp. 185-190, 2014.

[60] S. H. Kim, S. W. Lee, G. M. Lee, B.-T. Lee, S.-T. Yun, and S.-O. Kim, "Monitoring of $\mathrm{TiO}_{2}$-catalytic UV-LED photo-oxidation of cyanide contained in mine wastewater and leachate," Chemosphere, vol. 143, pp. 106-114, 2016.

[61] Z. P. Chen, Y. Li, M. Guo et al., "One-pot synthesis of Mn-doped $\mathrm{TiO}_{2}$ grown on graphene and the mechanism for removal of Cr(VI) and Cr(III)," Journal of Hazardous Materials, vol. 310, pp. 188-198, 2016.

[62] A. Mills and S. Le Hunte, "An overview of semiconductor photocatalysis," Journal of Photochemistry and Photobiology A: Chemistry, vol. 108, no. 1, pp. 1-35, 1997.

[63] H. A. Foster, I. B. Ditta, S. Varghese, and A. Steele, "Photocatalytic disinfection using titanium dioxide: spectrum and mechanism of antimicrobial activity," Applied Microbiology and Biotechnology, vol. 90, no. 6, pp. 1847-1868, 2011.

[64] M. Anpo, S. Kishiguchi, Y. Ichihashi et al., "The design and development of second-generation titanium oxide photocatalysts able to operate under visible light irradiation by applying a metal ion-implantation method," Research on Chemical Intermediates, vol. 27, no. 4-5, pp. 459-467, 2001.

[65] W. Mu, J.-M. Herrmann, and P. Pichat, "Room temperature photocatalytic oxidation of liquid cyclohexane into cyclohexanone over neat and modified $\mathrm{TiO}_{2}$," Catalysis Letters, vol. 3, no. 1, pp. 73-84, 1989.

[66] M. K. Seery, R. George, P. Floris, and S. C. Pillai, "Silver doped titanium dioxide nanomaterials for enhanced visible light photocatalysis," Journal of Photochemistry and Photobiology A: Chemistry, vol. 189, no. 2-3, pp. 258-263, 2007.

[67] K. Page, R. G. Palgrave, I. P. Parkin, M. Wilson, S. L. P. Savin, and A. V. Chadwick, "Titania and silver-titania composite films on glass-potent antimicrobial coatings," Journal of Materials Chemistry, vol. 17, no. 1, pp. 95-104, 2007.

[68] J.-P. Kim, I.-H. Cho, I.-T. Kim, C.-U. Kim, N. H. Heo, and S.H. Suh, "Manufacturing of anti-viral inorganic materials from colloidal silver and titanium oxide," Revue Roumaine de Chimie, vol. 51, no. 11, pp. 1121-1129, 2006.

[69] C.-C. Liu, Y.-H. Hsieh, P.-F. Lai, C.-H. Li, and C.-L. Kao, "Photodegradation treatment of azo dye wastewater by $\mathrm{UV} / \mathrm{TiO}_{2}$ process," Dyes and Pigments, vol. 68, no. 2-3, pp. 191-195, 2006.

[70] Q. Wang, X. Wang, Z. Wang, J. Huang, and Y. Wang, "PVDF membranes with simultaneously enhanced permeability and selectivity by breaking the tradeoff effect via atomic layer deposition of $\mathrm{TiO}_{2}$," Journal of Membrane Science, vol. 442, pp. 57-64, 2013. 
[71] S. Meng, J. Mansouri, Y. Ye, and V. Chen, "Effect of templating agents on the properties and membrane distillation performance of $\mathrm{TiO}_{2}$-coated PVDF membranes," Journal of Membrane Science, vol. 450, pp. 48-59, 2014.

[72] A. Razmjou, J. Mansouri, V. Chen, M. Lim, and R. Amal, “Titania nanocomposite polyethersulfone ultrafiltration membranes fabricated using a low temperature hydrothermal coating process," Journal of Membrane Science, vol. 380, no. 1-2, pp. 98-113, 2011.

[73] A. Razmjou, A. R. L. Holmes, H. Li, J. Mansouri, and V. Chen, "The effect of modified $\mathrm{TiO}_{2}$ nanoparticles on the polyethersulfone ultrafiltration hollow fiber membranes," Desalination, vol. 287, pp. 271-280, 2012.

[74] L. M. Hamming, R. Qiao, P. B. Messersmith, and L. C. Brinson, "Effects of dispersion and interfacial modification on the macroscale properties of $\mathrm{TiO}_{2}$ polymer-matrix nanocomposites," Composites Science and Technology, vol. 69, no. 11-12, pp. 1880-1886, 2009.

[75] S. Rajesh, S. Senthilkumar, A. Jayalakshmi, M. T. Nirmala, A. F. Ismail, and D. Mohan, "Preparation and performance evaluation of poly (amide-imide) and $\mathrm{TiO}_{2}$ nanoparticles impregnated polysulfone nanofiltration membranes in the removal of humic substances," Colloids and Surfaces A: Physicochemical and Engineering Aspects, vol. 418, pp. 92-104, 2013.

[76] W. Kangwansupamonkon, W. Jitbunpot, and S. Kiatkamjornwong, "Photocatalytic efficiency of $\mathrm{TiO}_{2} /$ poly[acrylamide-co(acrylic acid)] composite for textile dye degradation," Polymer Degradation and Stability, vol. 95, no. 9, pp. 1894-1902, 2010.

[77] E. Bet-Moushoul, Y. Mansourpanah, K. Farhadi, and M. Tabatabaei, " $\mathrm{TiO}_{2}$ nanocomposite based polymeric membranes: a review on performance improvement for various applications in chemical engineering processes," Chemical Engineering Journal, vol. 283, pp. 29-46, 2016.

[78] O. Sacco, M. Stoller, V. Vaiano, P. Ciambelli, A. Chianese, and D. Sannino, "Photocatalytic degradation of organic dyes under visible light on $\mathrm{N}$-doped $\mathrm{TiO}_{2}$ photocatalysts," International Journal of Photoenergy, vol. 2012, Article ID 626759, 8 pages, 2012.

[79] M. Stoller, L. Miranda, and A. Chianese, "Optimal feed location in a spinning disc reactor for the production of $\mathrm{TiO}_{2}$ nanoparticles," Chemical Engineering Transactions, vol. 17, pp. 993-998, 2009.

[80] A. Janotti and C. G. Van de Walle, "Fundamentals of zinc oxide as a semiconductor," Reports on Progress in Physics, vol. 72, no. 12, Article ID 126501, 2009.

[81] D. C. Reynolds, D. C. Look, B. Jogai, C. W. Litton, G. Cantwell, and W. C. Harsch, "Valence-band ordering in ZnO," Physical Review B-Condensed Matter and Materials Physics, vol. 60, no. 4, pp. 2340-2344, 1999.

[82] Y. Chen, D. M. Bagnall, H.-J. Koh et al., "Plasma assisted molecular beam epitaxy of $\mathrm{ZnO}$ on c-plane sapphire: growth and characterization," Journal of Applied Physics, vol. 84, no. 7, pp. 3912-3918, 1998.

[83] M. L. Schmidt and D. J. L. MacManus, "ZnO-nanostructures, defects, and devices," Materials Today, vol. 10, pp. 40-48, 2007.

[84] N. Daneshvar, D. Salari, and A. R. Khataee, "Photocatalytic degradation of azo dye acid red 14 in water on $\mathrm{ZnO}$ as an alternative catalyst to $\mathrm{TiO}_{2}$," Journal of Photochemistry and Photobiology A: Chemistry, vol. 162, no. 2-3, pp. 317-322, 2004.

[85] M. A. Behnajady, N. Modirshahla, and R. Hamzavi, "Kinetic study on photocatalytic degradation of C.I. Acid Yellow 23 by
ZnO photocatalyst," Journal of Hazardous Materials, vol. 133, no. 1-3, pp. 226-232, 2006.

[86] C. Gomez-Solís, J. C. Ballesteros, L. M. Torres-Martínez et al., "Rapid synthesis of $\mathrm{ZnO}$ nano-corncobs from Nital solution and its application in the photodegradation of methyl orange," Journal of Photochemistry and Photobiology A: Chemistry, vol. 298, pp. 49-54, 2015.

[87] K. M. Lee, C. W. Lai, K. S. Ngai, and J. C. Juan, "Recent developments of zinc oxide based photocatalyst in water treatment technology: a review," Water Research, vol. 88, pp. 428-448, 2016.

[88] M. Samadi, A. Pourjavadi, and A. Z. Moshfegh, "Role of $\mathrm{CdO}$ addition on the growth and photocatalytic activity of electrospun $\mathrm{ZnO}$ nanofibers: UV vs. visible light," Applied Surface Science, vol. 298, pp. 147-154, 2014.

[89] I.-T. Liu, M.-H. Hon, and L. G. Teoh, "The preparation, characterization and photocatalytic activity of radical-shaped $\mathrm{CeO}_{2} / \mathrm{ZnO}$ microstructures," Ceramics International, vol. 40, no. 3, pp. 4019-4024, 2014.

[90] M. T. Uddin, Y. Nicolas, C. Olivier et al., "Nanostructured $\mathrm{SnO}_{2}-\mathrm{ZnO}$ heterojunction photocatalysts showing enhanced photocatalytic activity for the degradation of organic dyes," Inorganic Chemistry, vol. 51, no. 14, pp. 7764-7773, 2012.

[91] H. R. Pant, C. H. Park, B. Pant, L. D. Tijing, H. Y. Kim, and C. S. Kim, "Synthesis, characterization, and photocatalytic properties of $\mathrm{ZnO}$ nano-flower containing $\mathrm{TiO}_{2} \mathrm{NPs}$, Ceramics International, vol. 38, no. 4, pp. 2943-2950, 2012.

[92] K. Dai, L. Lu, C. Liang et al., "Graphene oxide modified ZnO nanorods hybrid with high reusable photocatalytic activity under UV-LED irradiation," Materials Chemistry and Physics, vol. 143, no. 3, pp. 1410-1416, 2014.

[93] X. Zhou, T. Shi, and H. Zhou, "Hydrothermal preparation of $\mathrm{ZnO}$-reduced graphene oxide hybrid with high performance in photocatalytic degradation," Applied Surface Science, vol. 258, no. 17, pp. 6204-6211, 2012.

[94] Y. Lei, F. Chen, Y. Luo, and L. Zhang, "Three-dimensional magnetic graphene oxide foam $/ \mathrm{Fe}_{3} \mathrm{O}_{4}$ nanocomposite as an efficient absorbent for $\mathrm{Cr}(\mathrm{VI})$ removal," Journal of Materials Science, vol. 49, no. 12, pp. 4236-4245, 2014.

[95] L. Tan, J. Xu, X. Xue et al., "Multifunctional nanocomposite $\mathrm{Fe}_{3} \mathrm{O}_{4} @ \mathrm{SiO}_{2}-\mathrm{mPD} / \mathrm{SP}$ for selective removal of $\mathrm{Pb}$ (II) and $\mathrm{Cr}(\mathrm{VI})$ from aqueous solutions," RSC Advances, vol. 4, no. 86, pp. 45920-45929, 2014.

[96] A.-F. Ngomsik, A. Bee, D. Talbot, and G. Cote, "Magnetic solid-liquid extraction of $\mathrm{Eu}(\mathrm{III}), \mathrm{La}(\mathrm{III}), \mathrm{Ni}(\mathrm{II})$ and $\mathrm{Co}(\mathrm{II})$ with maghemite nanoparticles," Separation and Purification Technology, vol. 86, pp. 1-8, 2012.

[97] C. L. Warner, R. S. Addleman, A. D. Cinson et al., "Highperformance, superparamagnetic, nanoparticle-based heavy metal sorbents for removal of contaminants from natural waters," ChemSusChem, vol. 3, no. 6, pp. 749-757, 2010.

[98] F. Ge, M.-M. Li, H. Ye, and B.-X. Zhao, "Effective removal of heavy metal ions $\mathrm{Cd}^{2+}, \mathrm{Zn}^{2+}, \mathrm{Pb}^{2+}, \mathrm{Cu}^{2+}$ from aqueous solution by polymer-modified magnetic nanoparticles," Journal of Hazardous Materials, vol. 211-212, pp. 366-372, 2012.

[99] R. A. Khaydarov, R. R. Khaydarov, and O. Gapurova, "Water purification from metal ions using carbon nanoparticleconjugated polymer nanocomposites," Water Research, vol. 44, no. 6, pp. 1927-1933, 2010.

[100] H. Liang, B. Xu, and Z. Wang, "Self-assembled 3D flower-like $\alpha$ $\mathrm{Fe}_{2} \mathrm{O}_{3}$ microstructures and their superior capability for heavy 
metal ion removal," Materials Chemistry and Physics, vol. 141, no. 2-3, pp. 727-734, 2013.

[101] H. J. Shipley, K. E. Engates, and V. A. Grover, "Removal of Pb(II), $\mathrm{Cd}(\mathrm{II}), \mathrm{Cu}(\mathrm{II})$, and $\mathrm{Zn}(\mathrm{II})$ by hematite nanoparticles: effect of sorbent concentration, $\mathrm{pH}$, temperature, and exhaustion," Environmental Science and Pollution Research, vol. 20, no. 3, pp. 1727-1736, 2013.

[102] A. Chatterjee and B. L. Deopura, "Carbon nanotubes and nanofibre: an overview," Fibers and Polymers, vol. 3, no. 4, pp. 134-139, 2002.

[103] X. Peng, Y. Li, Z. Luan et al., "Adsorption of 1,2-dichlorobenzene from water to carbon nanotubes," Chemical Physics Letters, vol. 376, no. 1-2, pp. 154-158, 2003.

[104] C. Lu, F. S. Su, and S. Hu, "Surface modification of carbon nanotubes for enhancing BTEX adsorption from aqueous solutions," Applied Surface Science, vol. 254, no. 21, pp. 70357041, 2008.

[105] H.-H. Cho, K. Wepasnick, B. A. Smith, F. K. Bangash, D. H. Fairbrother, and W. P. Ball, "Sorption of aqueous $\mathrm{Zn}[\mathrm{II}]$ and Cd[II] by multiwall carbon nanotubes: the relative roles of oxygen-containing functional groups and graphenic carbon," Langmuir, vol. 26, no. 2, pp. 967-981, 2010.

[106] Y.-H. Li, J. Ding, Z. Luan et al., "Competitive adsorption of $\mathrm{Pb}^{2+}$, $\mathrm{Cu}^{2+}$ and $\mathrm{Cd}^{2+}$ ions from aqueous solutions by multiwalled carbon nanotubes," Carbon, vol. 41, no. 14, pp. 2787-2792, 2003.

[107] T. Madrakian, A. Afkhami, M. Ahmadi, and H. Bagheri, "Removal of some cationic dyes from aqueous solutions using magnetic-modified multi-walled carbon nanotubes," Journal of Hazardous Materials, vol. 196, pp. 109-114, 2011.

[108] Y.-L. Zhao and J. F. Stoddart, "Noncovalent functionalization of single-walled carbon nanotubes," Accounts of Chemical Research, vol. 42, no. 8, pp. 1161-1171, 2009.

[109] C.-M. Yang, J. S. Park, K. H. An et al., "Selective removal of metallic single-walled carbon nanotubes with small diameters by using nitric and sulfuric acids," Journal of Physical Chemistry B, vol. 109, no. 41, pp. 19242-19248, 2005.

[110] P. Z. Ray and H. J. Shipley, "Inorganic nano-adsorbents for the removal of heavy metals and arsenic: a review," RSC Advances, vol. 5, no. 38, pp. 29885-29907, 2015.

[111] A. S. Adeleye, J. R. Conway, K. Garner, Y. Huang, Y. Su, and A. A. Keller, "Engineered nanomaterials for water treatment and remediation: costs, benefits, and applicability," Chemical Engineering Journal, vol. 286, pp. 640-662, 2016.

[112] Y.-H. Li, S. Wang, J. Wei et al., "Lead adsorption on carbon nanotubes," Chemical Physics Letters, vol. 357, no. 3-4, pp. 263266, 2002.

[113] A. S. Adeleye and A. A. Keller, "Long-term colloidal stability and metal leaching of single wall carbon nanotubes: effect of temperature and extracellular polymeric substances," Water Research, vol. 49, pp. 236-250, 2014.

[114] V. K. Gupta, S. Agarwal, and T. A. Saleh, "Chromium removal by combining the magnetic properties of iron oxide with adsorption properties of carbon nanotubes," Water Research, vol. 45, no. 6, pp. 2207-2212, 2011.

[115] A. Azari, A.-A. Babaei, R. R. Kalantary, A. Esrafili, M. Moazzen, and B. Kakavandi, "Nitrate removal from aqueous solution using carbon nanotubes magnetized by nano zero-valent iron," Journal of Mazandaran University of Medical Sciences, vol. 23, no. 2, pp. 14-27, 2014.

[116] M. Peyravi, M. Jahanshahi, A. Rahimpour, A. Javadi, and S. Hajavi, "Novel thin film nanocomposite membranes incorporated with functionalized $\mathrm{TiO}_{2}$ nanoparticles for organic solvent nanofiltration," Chemical Engineering Journal, vol. 241, pp. 155-166, 2014.

[117] S. J. Tesh and T. B. Scott, "Nano-composites for water remediation: a review," Advanced Materials, vol. 26, no. 35, pp. 60566068, 2014.

[118] X. Ma, A. Gurung, and Y. Deng, "Phytotoxicity and uptake of nanoscale zero-valent iron (nZVI) by two plant species," Science of the Total Environment, vol. 443, pp. 844-849, 2013.

[119] X. L. Chen, J. O'Halloran, and M. A. K. Jansen, “The toxicity of zinc oxide nanoparticles to Lemna minor (L.) is predominantly caused by dissolved Zn," Aquatic Toxicology, vol. 174, pp. 46-53, 2016.

[120] F. M. Li, Z. Liang, X. Zheng, W. Zhao, M. Wu, and Z. Y. Wang, "Toxicity of nano- $\mathrm{TiO}_{2}$ on algae and the site of reactive oxygen species production," Aquatic Toxicology, vol. 158, pp. 1-13, 2015. 

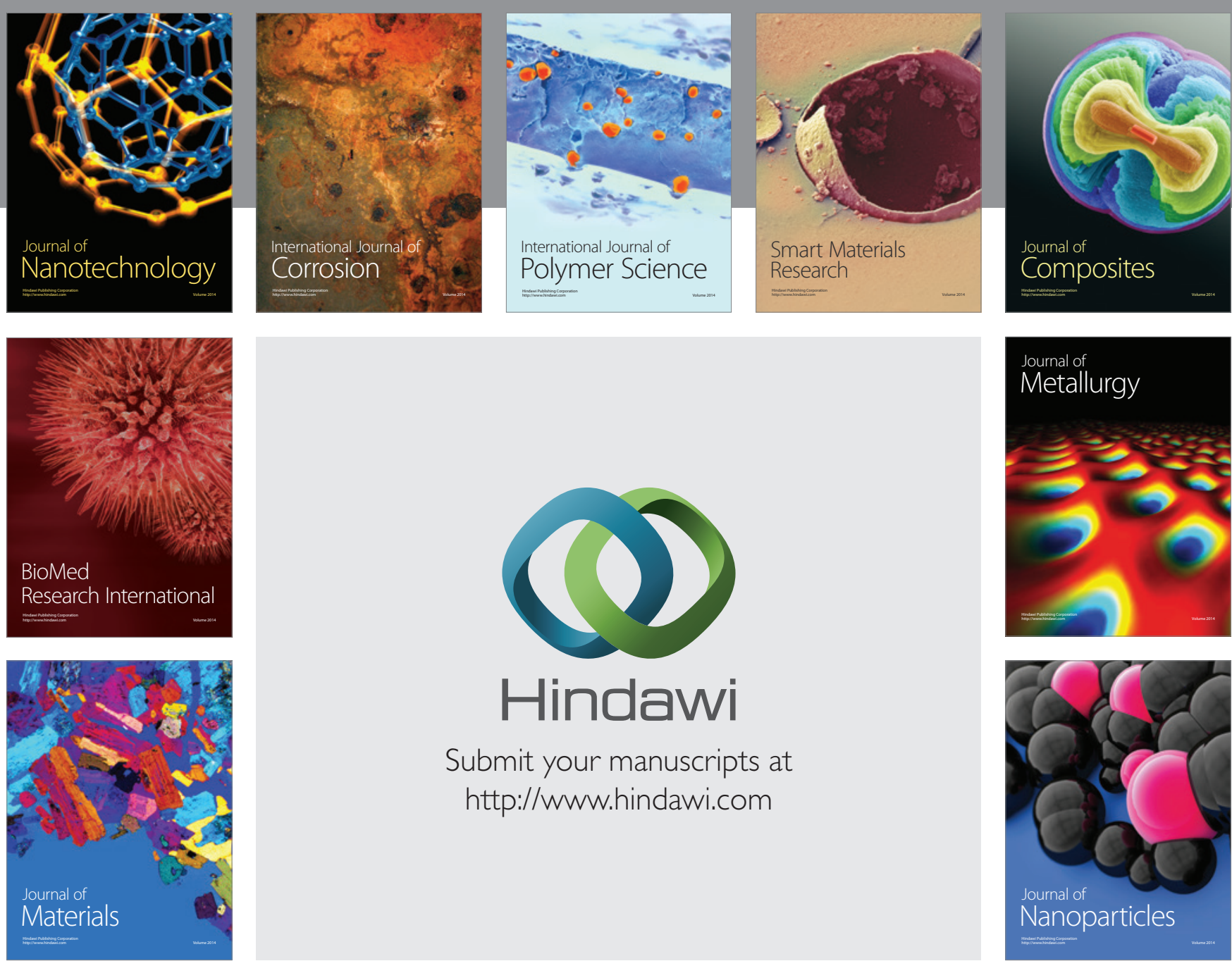

\section{Hindawi}

Submit your manuscripts at

http://www.hindawi.com

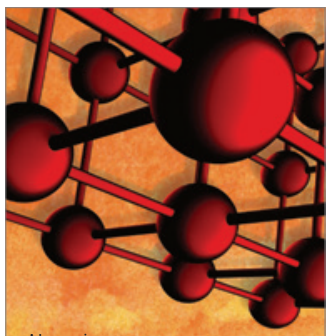

Materials Science and Engineering
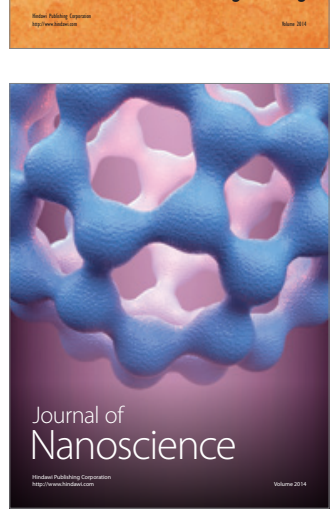
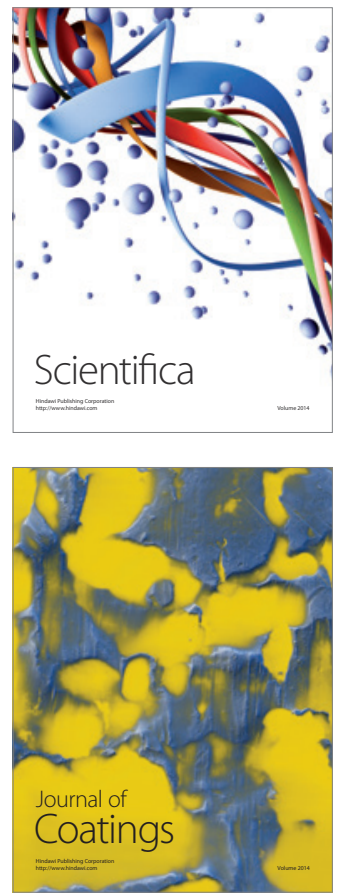
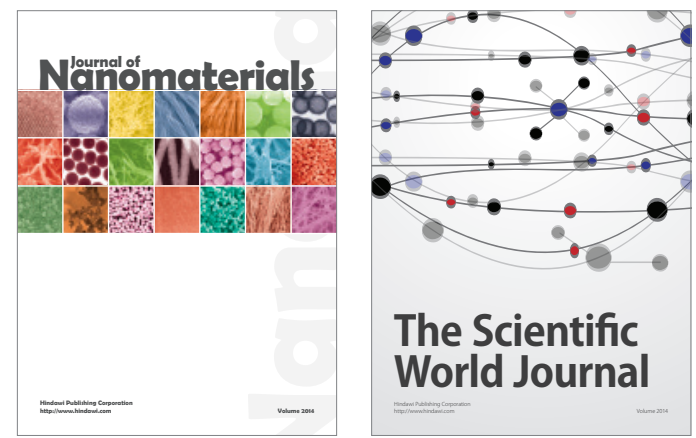

The Scientific World Journal
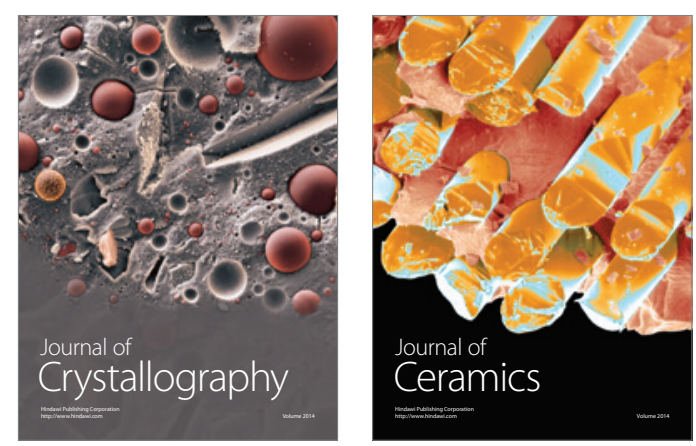
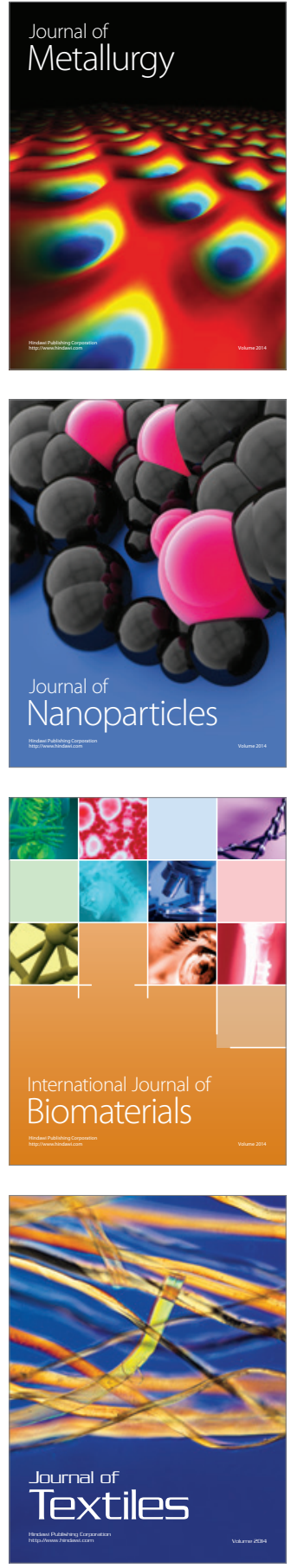